\title{
STUDI EMPIRIS PERILAKU KEPATUHAN PAJAK \\ PADA WAJIB PAJAK ORANG PRIBADI (STUDI PADA KPP PARATAMA PAMEKASAN)
}

\author{
Astri Furqani, S.E., M.Ak. ${ }^{1}$ \\ Norsain, S.E., M.Ak.2 ${ }^{2}$ \\ ${ }^{1}$ Fakultas Ekonomi dan Bisnis, Universitas Wiraraja \\ as3oke_dech@yahoo.com \\ ${ }^{2}$ Fakultas Ekonomi dan Bisnis, Universitas Wiraraja \\ norsain@yahoo.com
}

\begin{abstract}
Tax compliance issue is a classic problem encountered in almost all the countries that apply the taxation system. Ongoing reforms in government taxation which includes the formulation and manufacture of legislation and improvement of tax administration that facilitate services for the taxpayer. The question, after all this time self-assessment system is running, why the level of compliance has not yet reached the optimum level? What drives someone to be obedient and disobedient?

This study using convenience sampling method with a sample of 225 respondents individual taxpayer listed on STO Pamekasan.

The results showed there are significant variable level of education and income level of the Compliance Tax. SPSS test results, that after the simultaneous analysis of independent variables significantly influence the dependent variable at the level of 5\% (0.05). $R$ Square $=0.154$ showed $15 \%$ variation Tax Compliance influenced by education level variables and variable rate income and the rest influenced by other factors not known to include error. With a significance level of 5\%, the variable $X$ which significantly affect the $Y$ variable is the variable XI only to Education for sign value $<0.05$ while the variable rate income $>0.05$
\end{abstract}

Keywords: tax compliance, education level, income level

\section{PENDAHULUAN}

Salah satu instrumen kebijakan fiskal yang dinamis adalah perpajakan. Untuk meningkatkan kepatuhan wajib pajak dapat dilakukan dari berbagai aspek, seperti dari aspek ekonomi maupun dari aspek psikologis.

Gunadi (2005) juga menyatakan bahwa tax ratio di Indonesia masih berada dibawah angka rata-rata $20 \%$ capaian tax rasio internasional. Berdasar pada penelitian-penelitian yang telah ada sebelumnya sehingga peneliti tertarik untuk meneliti tingkat kepatuhan WP orang pribadi yang berada di wilayah KPP Pratama Pamekasan jika ditinjau dari tingkat pendidikan maupun dari tingkat penghasilan baik diuji secara parsial maupun secara simultan.

\section{Kepatuhan Pajak}

Ketidakpatuhan pajak bisa saja dilakukan dengan cara tidak melaporkan kondisi yang sesungguhnya atas jumlah yang dikenai pajak. Dan ketidakpatuhan pajak dapat disebabkan baik dari faktor internal atau eksternal individu. 


\section{FAKULTAS EKONOMI DAN BISNIS UNIVERSITAS WIRARAJA SUMENEP - MADURA}

\section{Tingkat Pendidikan}

Terdapat beberapa asumsi di masyarakat bahwa seseorang yang memiliki tingkat pendidikan rendah berpeluang tidak mematuhi kewajiban pajak yang dikarenakan ketidakpahaman terhadap sistem perpajakan yang berlaku. Sedangkan mereka yang memiliki tingkat pendidikan yang tinggi cenderung untuk mematuhi kewajiban pajak dikarenakan dianggap lebih mudah untuk memahami peraturan sistem perpajakan yang diterapkan.

\section{Tingkat Penghasilan}

Beberapa hasil riset menunjukkan bahwa tingkat penghasilan mempengaruhi tingkat kepatuhan Wajib Pajak. Hal tersebut bisa saja dikarenakan pajak terutang didasarkan atas tingkat penghasilan wajib pajak sebagai objek pajak penghasilan. Membayar pajak secara tepat waktu juga dapat dipengaruhi oleh tingkat penghasilan wajib pajak.

\section{Metode Penelitian}

Penelitian ini menggunakan sampel WP orang pribadi yang telah terdaftar pada KPP Pratama Pemekasan meliputi Kabupaten Sumenep dan
Kabupaten Pamekasan. Adapun teknik pengumpulan data menggunakan data primer melalui penyebaran kuesioner (skala likert) yang dibagikan kepada responden.

Peneliti menggunakan model penelitian analisis regresi berganda dengan program SPSS.

Persamaan yang dapat dirumuskan berdasarkan hipotesis yang dikembangkan adalah sebagai berikut.

$\mathrm{Y}=\alpha+\beta \mathrm{X} 1+\beta \mathrm{X} 2+\beta \mathrm{X} 3+\varepsilon$ dimana, $\mathrm{Y}=$ KemauanMembayarPajak (Willingness to Pay Tax)

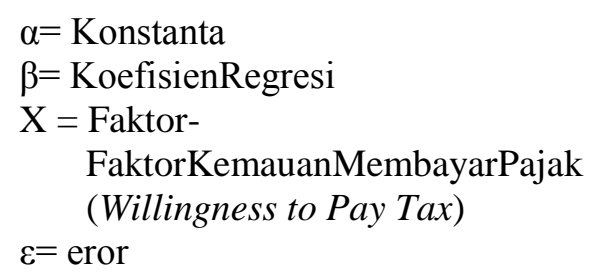

\section{ANALISIS DATA DAN}

PEMBAHASAN

\section{Demografi Responden.}

Tabel dibawah ini menyajikan beberapa informasi umum tentang kondisi responden (wajib pajak orang pribadi yang terdaftar di KPP Pratama Pamekasan) 


\section{Kerangka Pikir}

Berikut kerangka pikir dalam penelitian ini:

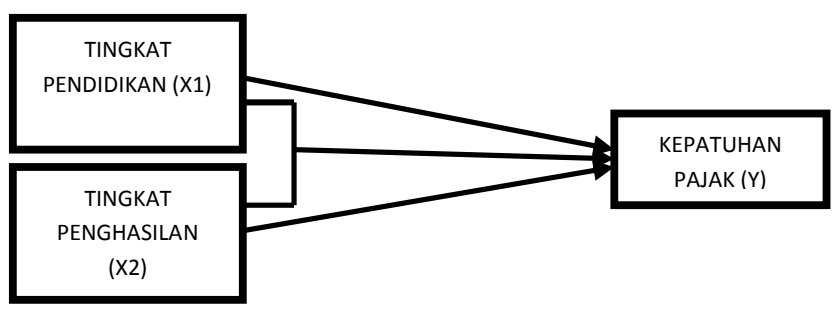

Tabel 11

Data Responden

\begin{tabular}{|c|c|c|c|c|}
\hline No & Responden & Keterangan & $\mathrm{S}$ & $\%$ \\
\hline \multirow[t]{6}{*}{1} & Pendidikan & SD & 9 & $4 \%$ \\
\hline & & SMP & 17 & $7,5 \%$ \\
\hline & & SMA & 85 & $37,8 \%$ \\
\hline & & Diploma & 27 & $12 \%$ \\
\hline & & Sarjana & 87 & $38,7 \%$ \\
\hline & \multicolumn{2}{|l|}{ Jumlah } & 225 & $100 \%$ \\
\hline \multirow[t]{6}{*}{2} & Usia & $15 \mathrm{sd} 20$ th & 20 & $8.9 \%$ \\
\hline & & $21 \mathrm{sd} 25$ th & 17 & $7.5 \%$ \\
\hline & & 26 sd 30 th & 20 & $8.9 \%$ \\
\hline & & $31 \mathrm{sd} 35$ th & 53 & $23.6 \%$ \\
\hline & & Diatas 35 th & 115 & $51.1 \%$ \\
\hline & \multicolumn{2}{|l|}{ Jumlah } & 225 & $100 \%$ \\
\hline \multirow[t]{6}{*}{3} & Penghasilan & Kurang $50 \mathrm{jt}$ & 51 & $22.7 \%$ \\
\hline & & $50 \mathrm{jt} \mathrm{sd} 100 \mathrm{jt}$ & 131 & $58.2 \%$ \\
\hline & & $100 \mathrm{jt} \mathrm{sd} 250 \mathrm{jt}$ & 33 & $14.7 \%$ \\
\hline & & $250 \mathrm{jt} \mathrm{sd} 500 \mathrm{jt}$ & 9 & $4 \%$ \\
\hline & & Diatas $500 \mathrm{jt}$ & 1 & $0.4 \%$ \\
\hline & Jumlah & & 225 & $100 \%$ \\
\hline
\end{tabular}

2. Uji Validitas dan Reliabilitas.

Didapatkan hasil uji reliabilitas nilai koefisien cronbach alpha $76,7 \%$ yang menurut kriteria Nunnally bisa dikatakan reliabel.

Hasil uji validitas pada semua indicator $\mathrm{Y}$ corrected item total correlation ( $\mathrm{r}$ hitung) $>0,3$ sehingga dapat disimpulkan bahwa variable tersebut valid.

Korelasi antara masing-masing indikator terhadap total skor konstruk hasil output SPSS menunjukkan signifikan. Sehingga dapat disimpulkan bahwa masingmasing indikator pertanyaan adalah valid. 


\section{Uji Asumsi Klasik}

\section{a. Uji Normalitas}

Tabel 4.5

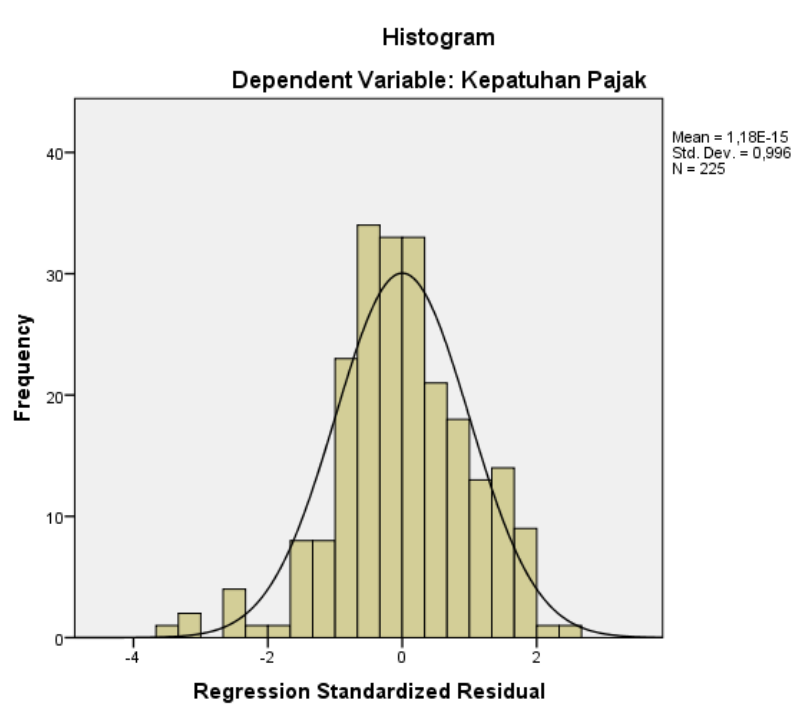

Dari grafik histogram pada tabel Tolerance sebesar 0,994 atau <1, yang 4.5 dapat disimpulkan bahwa grafik berarti tidak terjadi multikolinieritas antara variable independen dalam model regresi sehingga dapat dilanjutkan pada tahap analisa model regresi.

\section{Uji Heteroskedastisitas}

\section{b. Uji Multikolinieritas}

Berdasarkan hasil uji

Gambar scatterplot dibawah ini, multikolinieritas juga telah memenuhi persyaratan karena nilai VIF untuk tingkat penghasilan maupun tingkat pendidikan yaitu sebesar 1,006 atau dengan kata lain < 10 dan nilai menunjukkan tidak terdapat pola yang jelas, dan titik-titik menyebar secara acak diatas dan dibawah angka nol pada sumbu $\mathrm{y}$, sehingga tidak terjadi Heteroskedastisitas. 


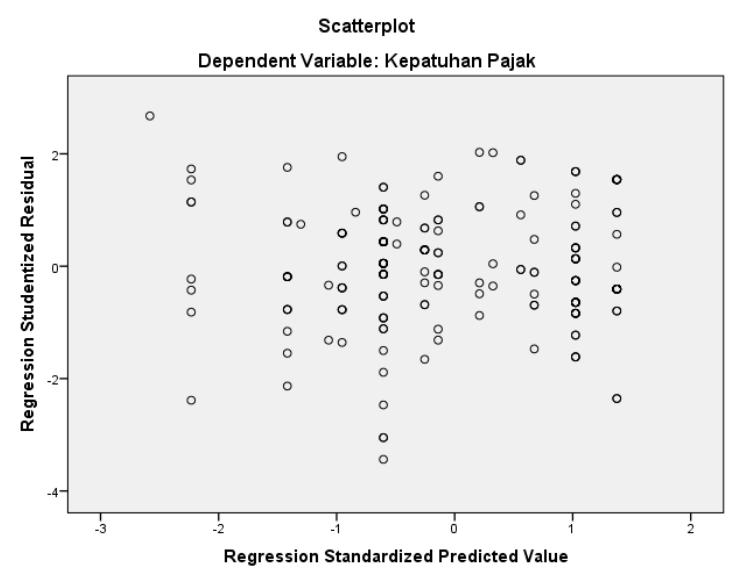

\section{d. Uji Autokorelasi}

Melihat hasil uji autokorelasi dengan $\mathrm{X}=2$ dan $\mathrm{n}=225$ maka $\mathrm{dl}=1.748$ dan du 1,789 hasil durbin watsonnya menunjukkan 1,496 dan berada pada jarak antara dl-du yang artinya tidak terdeteksi adanya autokorelasi

\section{e. Uji Linieritas}

Scatterplot

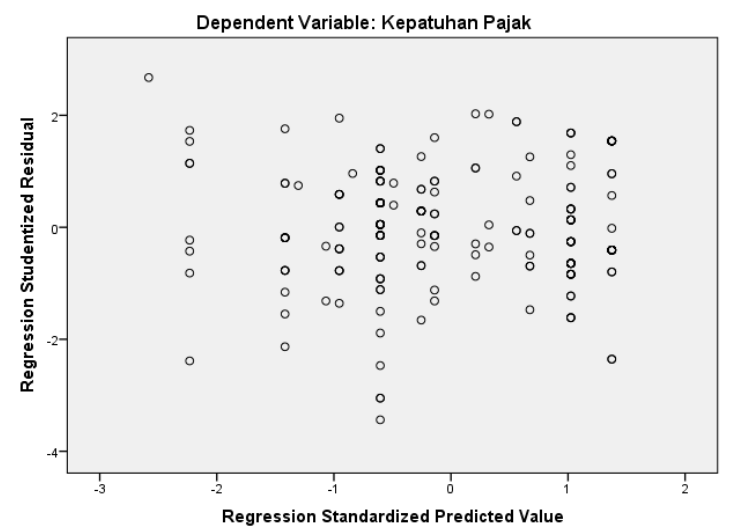

Regresi Linier Berganda

\section{a. Koefisien Determinasi}

Tabel diatas yang menunjukkan Model Summary dapat dilihat $\mathrm{R}=0,392$ menunjukkan adanya korelasi yang cukup antar semua variable $\mathrm{X}$ dan Variabel Y. $\mathrm{R} \quad$ Square $=0,154$ menunjukkan $15 \%$ variasi Kepatuhan
Pajak dipengaruhi oleh variabel Tingkat Pendidikan dan variabel Tingkat Penghasilan dan sisanya dipengaruhi oleh faktor lain yang tidak diketahui termasuk error. 


\section{FAKULTAS EKONOMI DAN BISNIS UNIVERSITAS WIRARAJA SUMENEP - MADURA}

\section{b. Uji Parsial}

Dari uji t pada tabel dibawah ini dapat dilihat variabel $\mathrm{X}$ yang signifikan berpengaruh terhadap $\mathrm{Y}$ hanya
X1(tingkat pendidikan) karena nilai sign $<0,05$ sedangkan variabel $\mathrm{X} 2$

(tingkat penghasilan) > 0,05 .

\section{Coefficients $^{\mathrm{a}}$}

\begin{tabular}{|c|c|c|c|c|c|}
\hline \multirow[t]{2}{*}{ Model } & \multicolumn{2}{|c|}{ Unstandardized Coefficients } & \multirow{2}{*}{$\begin{array}{c}\text { Standardized } \\
\text { Coefficients } \\
\text { Beta }\end{array}$} & \multirow[t]{2}{*}{$\mathrm{T}$} & \multirow[t]{2}{*}{ Sig. } \\
\hline & B & Std. Error & & & \\
\hline (Constant) & 3,392 & 156 & & 21,754 & ,000 \\
\hline 1 Tingkat Pendidikan & 179 & ,030 & ,371 & 5,990 & ,000 \\
\hline Tingkat Penghasilan &,- 077 & ,047 & -100 & $-1,620$ & 107 \\
\hline
\end{tabular}

a. Dependent Variable: Kepatuhan Pajak

Dari table di atas juga dapat diketahui bahwa Konstanta b0 $=3,392$ yang artinya jika variabel Tingkat pendidikan, variabel Tingkat penghasilan nilainya 0 maka kepatuhan pajak sebesar 3,392. Koefisien b1 = 0,179 , artinya jika variable Tingkat penghasilan ditingkatkan sebesar satu
(1), maka Kepatuhan Pajak akan meningkat sebesar 0,179.

Koefisien b2 $=-0,077$, artinya jika Tingkat pendidikan nilainya tetap dan variabel Tingkat penghasilan ditingkatkan satu (1), maka Kepatuhan Pajak akan menurun sebesar -0,077.

\section{Model Summary ${ }^{\mathrm{b}}$}

\begin{tabular}{|c|c|c|c|c|c|}
\hline Model & $\mathrm{R}$ & R Square & Adjusted R Square & $\begin{array}{c}\text { Std. Error of the } \\
\text { Estimate }\end{array}$ & $\begin{array}{c}\text { Durbin- } \\
\text { Watson }\end{array}$ \\
\hline 1 &, $392^{\mathrm{a}}$ &, 154 &, 146 &, 51774 & 1,496 \\
\hline
\end{tabular}

a. Predictors: (Constant), Tingkat Penghasilan, Tingkat Pendidikan

b. Dependent Variable: Kepatuhan Pajak

$$
\mathrm{Y}=3,392+0,179 \mathrm{X} 1-0,077 \mathrm{X} 2+\varepsilon
$$

dari hasil tersebut maka dapat dibentuk persamaan regresi berganda berikut ini: 


\section{FAKULTAS EKONOMI DAN BISNIS UNIVERSITAS WIRARAJA SUMENEP - MADURA}

\section{c. Uji Kecocokan Model/Simultan}

Dari hasil uji $\mathrm{F}$ diperoleh nilai signifikansi 0,00 artinya model regresi yang terbentuk cocok. Dan setelah dilakukan analisa secara simultan/bersama-sama semua variable independen signifikan berpengaruh terhadap variable dependen di level $5 \%$. Dan terbukti dari hasil signifikansinya yaitu $0,000<0,05$. Dengan kata lain menunjukkan bahwa terdapat pengaruh antara variabel tingkat pendidkan dan tingkat penghasilan terhadap kepatuhan WP pada KPP Pratama Pamekasan.

Hasil uji parsial juga telah menunjukkan bahwa antara tingkat pendidikan dan dan tingkat penghasilan yang dapat mempengaruhi kepatuhan WP pada KPP Pratama Pamekasan adalah tingkat pendidikan. Prosentase tertinggi data pengisi kuesioner juga menunjukkan bahwa sebanyak 38,7\% berlatar pendidikan sebagai sarjana, $12 \%$ berlatar pendidikan diploma, sehingga lebih dari $50 \%$ yang memiliki pendidikan di atas tingkat SMA dengan demikian dapat mempengaruhi hasil pengaruh tingkat pendidikan terhadap tingkat kepatuhan WP. Dan hal tersebut sesuai dengan asumsi sebelumnya yang menyatakan bahwa seseorang yang memiliki tingkat pendidikan yang tinggi akan lebih mudah untuk memahami sistem peraturan perpajakan yang berlaku.
Sedangkan tingkat penghasilan tidak berpengaruh terhadap kepatuhan WP dikarenakan pajak terutang didasarkan atas tingkat penghasilan wajib pajak sebagai objek pajak penghasilan dan hal tersebut sejalan dengan hasil penelitian yang dilakukan oleh Syafiqurrahman dan Sri Suranta (2006).

\section{KESIMPULAN}

1. Terdapat pengaruh antara variabelvariabel Tingkat pendidikan dan variable Tingkat penghasilan terhadap Kepatuhan Pajak.Dari hasil uji SPSS, bahwa setelah dilakukan analisa secara simultan/ bersama-sama semua variable independen signifikan berpengaruh terhadap variable dependen. Terbukti dengan hasil signifikansinya $0,000<0,05$.

2. Dengan tingkat signifikansi $5 \%$, variable $\mathrm{X}$ yang signifikan berpengaruh terhadap variabel $\mathrm{Y}$ hanya X1 yaitu variabel Tingkat Pendidikan karena nilai sign $<0,05$ sedangkan variable Tingkat penghasilan $>0,05$. 
3. $\mathrm{R}=0,392$ menunjukkan adanya korelasi yang cukup antar semua variable X dan Variabel Y. R Square $=0,154$ menunjukkan $15 \%$ variasi Kepatuhan Pajak dipengaruhi oleh variabel Tingkat Pendidikan dan variabel Tingkat Penghasilan dan sisanya dipengaruhi oleh faktor lain yang tidak diketahui termasuk error.

\section{SARAN}

Berdasarkan kesimpulan diatas, berikut beberapa saran yang bisa dijadikan sebagai pertimbangan dalam penelitian berikutnya diantaranya :

1. Objek ditambah dengan WP orang pribadi yang melakukan pekerjaan bebas atau badan
2. Terdapat penelitian lanjutan dengan membandingkan faktor yang mempengaruhi kepatuhan WP orang pribadi dan badan.

\section{DAFTAR PUSTAKA}

Erly Suandy. 2014. Hukum Pajak. Edisi 6. Salemba Empat. Jakarta

Mardiasmo. 2015. Perpajakan Edisi Revisi. Andi Publisher

Suafiqurrahman, Muhammad dan Sri Suranta.2006. Analisis FaktorFaktor yang Mempengaruhi Wajib Pajak terhadap Kepatuhan Membayar Pajak Restoran di Surakarta.

Yustinus Prastowo. 2008. Manfaat dan Risiko Memiliki NPWP. Raih Asa Sukses 